\title{
Satellite observations of formaldehyde over North America from GOME
}

\section{Citation}

Chance, Kelly, Paul I. Palmer, Robert J. D. Spurr, Randall V. Martin, Thomas P. Kurosu, and Daniel J. Jacob. 2000. "Satellite Observations of Formaldehyde over North America from GOME." Geophys. Res. Lett. 27 (21) (November 1): 3461-3464. doi:10.1029/2000gl011857.

\section{Published Version}

doi:10.1029/2000GL011857

\section{Permanent link}

http://nrs.harvard.edu/urn-3:HUL.InstRepos:14061859

\section{Terms of Use}

This article was downloaded from Harvard University's DASH repository, and is made available under the terms and conditions applicable to Other Posted Material, as set forth at http:// nrs.harvard.edu/urn-3:HUL.InstRepos:dash.current.terms-of-use\#LAA

\section{Share Your Story}

The Harvard community has made this article openly available.

Please share how this access benefits you. Submit a story.

Accessibility 


\title{
Satellite observations of formaldehyde over North America from GOME
}

\author{
Kelly Chance ${ }^{1}$, Paul I. Palmer ${ }^{2}$, Robert J.D. Spurr ${ }^{1}$, Randall V. Martin², \\ Thomas P. Kurosu ${ }^{1}$, and Daniel J. Jacob ${ }^{2}$
}

Abstract. Formaldehyde (HCHO) is an important indicator of tropospheric hydrocarbon emissions and photochemical activity. We present $\mathrm{HCHO}$ observations over North America for July 1996 from the GOME instrument on-board the ESA ERS-2 satellite. Slant columns are determined to $<4 \times 10^{15}$ molecules $\mathrm{cm}^{-2}$ sensitivity by directly fitting GOME radiance measurements. These show a distinct enhancement over the southeastern United States, consistent with a large regional source from oxidation of non-methane hydrocarbons including in particular isoprene. Conversion of slant to vertical columns is done by combining species vertical distribution information from the GEOS-CHEM 3$\mathrm{D}$ tropospheric chemistry and transport model with scattering weights from the Smithsonian Astrophysical Observatory LIDORT multiple scattering radiative transfer model. The results demonstrate the ability to measure HCHO from space in typical continental atmospheres, and imply that space-based measurements of $\mathrm{HCHO}$ may provide valuable information on emission fluxes of reactive hydrocarbons.

\section{Introduction}

Formaldehyde ( $\mathrm{HCHO}$ ) is a principal intermediate in the oxidation of hydrocarbons in the troposphere. Oxidation of methane $\left(\mathrm{CH}_{4}\right)$ by the hydroxyl radical $(\mathrm{OH})$ is the principal source of $\mathrm{HCHO}$ in most of the troposphere; loss of $\mathrm{HCHO}$ is mainly by photolysis and reaction with $\mathrm{OH}$. The corresponding atmospheric lifetime of $\mathrm{HCHO}$ is of the order of hours [Logan et al., 1981]. Since $\mathrm{CH}_{4}$ concentrations are relatively constant in the troposphere and photolysis is the dominant $\mathrm{HCHO}$ sink, when $\mathrm{CH}_{4}$ is the dominant source a strong correlation is expected between $\mathrm{HCHO}$ concentrations and 24-hour average $\mathrm{OH}$ concentrations. Under these conditions, $\mathrm{HCHO}$ serves as a proxy for tropospheric $\mathrm{OH}$ [Staffelbach et al., 1991].

In continental boundary layers, non-methane hydrocarbons (NMHCs) emitted by biogenic and anthropogenic sources usually dominate over $\mathrm{CH}_{4}$ as a source of $\mathrm{HCHO}$ [Munger et al., 1995; Lee et al., 1998] and make a large contribution to the HCHO atmospheric column. There is considerable uncertainty regarding NMHC emission fluxes. National U.S. emission estimates of biogenic isoprene, an important precursor for ozone $\left(\mathrm{O}_{3}\right)$ smog, have increased by a factor of 5 over the past decade [Guenther et al., 2000]. Emissions

\footnotetext{
${ }^{1}$ Harvard-Smithsonian Center for Astrophysics, Cambridge, MA

${ }^{2}$ Division of Applied Sciences, and Department of Earth and Planetary Sciences, Harvard University, Cambridge, MA
}

Copyright 2000 by the American Geophysical Union.

Paper number 2000GL011857.

0094-8276/00/2000GL011857\$05.00 of other biogenic NMHCs are even more uncertain. Inventories of NMHC emissions from automobiles are also difficult to constrain [Pierson et al., 1990]. These uncertainties represent a major weakness in our ability to model ozone production [McKeen et al., 1991], OH concentrations [McKeen et al., 1997], formation of organic nitrates [Moxim et al., 1996], and formation of organic aerosol [Penner, 1995]. Because $\mathrm{HCHO}$ is a major product of NMHC oxidation and its lifetime is short, it provides a diagnostic of integrated NMHC emissions and thus a test of emission inventories.

The Global Ozone Monitoring Experiment (GOME), launched on the ERS-2 satellite in April, 1995, obtains about 30,000 Earth radiance spectra each day. Spectra cover the ultraviolet $(237-405 \mathrm{~nm}$ at $0.2 \mathrm{~nm}$ resolution) and the visible (407-794 $\mathrm{nm}$ at $0.4 \mathrm{~nm}$ resolution) [Burrows et al., 1993; European Space Agency, 1995]. Current operational data products available for GOME include total columns of $\mathrm{O}_{3}$ and $\mathrm{NO}_{2}$, and cloud fractional coverage.

Preliminary $\mathrm{HCHO}$ measurement capability has been presented for GOME in Thomas et al. [1998]. We demonstrate here that it is now possible to determine $\mathrm{HCHO}$ columns from GOME spectra to sufficient precision (a factor of 4 to 5 improvement) for it to be used in detailed process studies as a tracer of NMHC emissions to the troposphere. The analysis method described here is applied to HCHO over North America in July 1996, where the source from oxidation of isoprene is expected to be particularly large over the southeastern U.S. [Lee et al., 1998]. Under these conditions, most of the $\mathrm{HCHO}$ atmospheric column seen by GOME is in the continental boundary layer (this, and the details of the air-mass factor determination, are described in Palmer, P.I., D.J. Jacob, K. Chance, R.V. Martin, R.J.D. Spurr, T.P. Kurosu, I. Bey, R. Yantosca, A. Fiore, and Q. Li, Air-mass factor formulation for spectroscopic measurements from satellites: Application to formaldehyde retrievals from GOME, submitted to J. Geophys. Res., 2000 - hereafter, PIP), so that the GOME measurements offer a proxy for emissions of NMHCs including in particular isoprene.

\section{Spectrum Fitting}

Vertical columns amounts of HCHO are determined in a two-step procedure. GOME radiance spectra are fitted first using a nonlinear least-squares inversion based on the Levenberg-Marquardt method [Press et al., 1986]. The fitting process determines the slant column amounts that minimize the $\chi^{2}$ error between observed and calculated GOME radiances. Second, a combination of radiative transfer calculations using the Smithsonian Astrophysical Observatory (SAO) LIDORT code [Spurr et al., 2000] and results from the GEOS-CHEM global 3-D model of tropospheric chemistry and transport [Bey et al., 1999] is used to determine the appropriate air-mass factors (AMFs) which convert the 

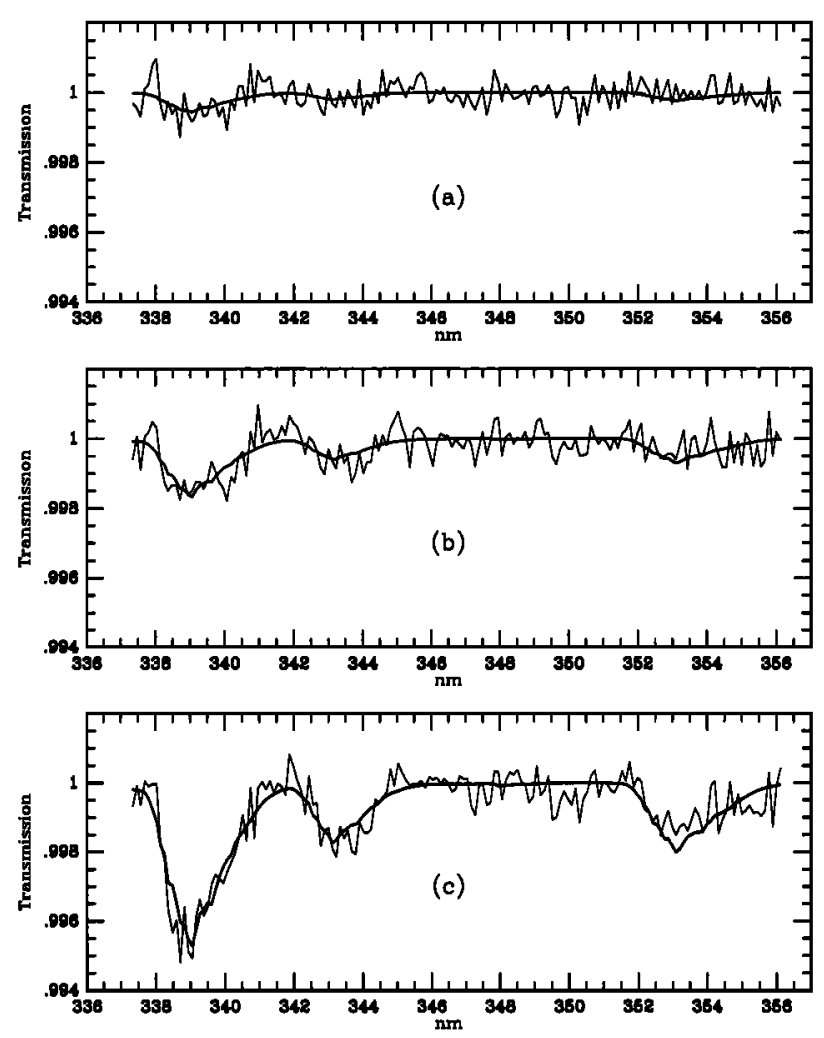

Figure 1. Fitting of HCHO in GOME orbit 70927023 for low, medium, and high $\mathrm{HCHO}$ amounts. (a) HCHO slant column $=1.0 \pm 0.3 \times 10^{16}$ molecules $\mathrm{cm}^{-2}$; (b) HCHO slant column $=3.0 \pm 0.4 \times 10^{16}$ molecules $\mathrm{cm}^{-2}$; (c) HCHO slant column $=$ $8.4 \pm 0.7 \times 10^{16}$ molecules $\mathrm{cm}^{-2}$. Uncertainties from spectrum fitting and cross sections (including temperature dependence) are included. Absorptions for the fitted HCHO amounts are shown with and without the fitting residuals to allow vizualization of the fitting quality.

fitted slant columns to vertical column abundances. The GEOS-CHEM model uses assimilated meteorological data for July 1996. Vertical profiles of HCHO are sampled from that model for the time and location of each GOME observation. The AMF calculations are described in a separate paper (PIP).

HCHO slant columns are determined from GOME spectra by direct fitting of GOME radiances, as described in Chance [1998]. Individual radiance spectra are fitted, with no smoothing or filtering applied, over the wavelength region $337.35-356.12 \mathrm{~nm}$. This fitting window was determined as the optimum compromise between large intensity for the HCHO cross sections and small spectral interference; it is slightly different from that used in Thomas et al. [1998]. Reference spectra for $\mathrm{HCHO}$, including linear temperature dependence, are from Cantrell et al. [1990]. The fitting includes the interfering species $\mathrm{O}_{3}, \mathrm{NO}_{2}, \mathrm{BrO}$, and the $\mathrm{O}_{2}-\mathrm{O}_{2}$ collision complex. $\mathrm{O}_{3}$ and $\mathrm{BrO}$ are fitted in separately optimized spectral windows, where their stronger absorption features are located, in order to determine their contributions in the HCHO fitting window as accurately as possible. The Ring effect is included as described in Chance and Spurr [1997]. Wavelength calibration of the GOME radiance and irradiance spectra in the level $1 \mathrm{~b}$ operational data products is not sufficiently accurate to permit fitting to the required levels. It is improved by using cross-correlation with the Fraunhofer reference spectrum [Caspar and Chance, 1997].

The GOME instrument suffers from substantial spectral undersampling. In regions where the atmospheric absorption is weak (e.g., that employed for HCHO fitting) this can largely be corrected using an undersampling correction spectrum generated by resampling an independent, highresolution Fraunhofer reference spectrum [Chance, 1998; Slijkhuis et al., 1999]. The resulting HCHO fits have residual rms values of typically $5 \times 10^{-4}$ of the full-scale GOME radiance spectrum.

HCHO slant columns are determined to $<4.0 \times 10^{15}$ molecules $\mathrm{cm}^{-2}$ fitting precision ( $1 \sigma$ uncertainties are used throughout). Overall accuracies are determined by adding $5 \%$ uncertainty for the HCHO cross sections [Cantrell et al., 1990 ] to the uncertainty from the fitting procedure, which is determined from the covariance matrix of the fitting errors and the rms of the fitting residuals. The fitting uses $300 \mathrm{~K}$ cross sections. An additional $5 \%$ uncertainty is included to account for the temperature dependence of the cross sections; their integral changes by $5 \%$ over our spectral fitting range in going from $300 \mathrm{~K}$ to $270 \mathrm{~K}$. This temperature range is appropriate for the HCHO observations presented here, considering that the bulk of the HCHO column is in the lower troposphere (PIP). Figure 1 shows spectral fitting examples

(a)

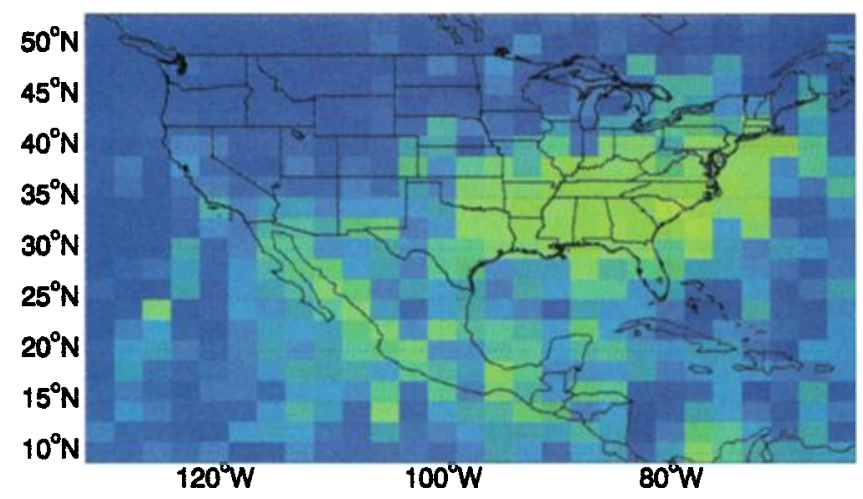

(b)

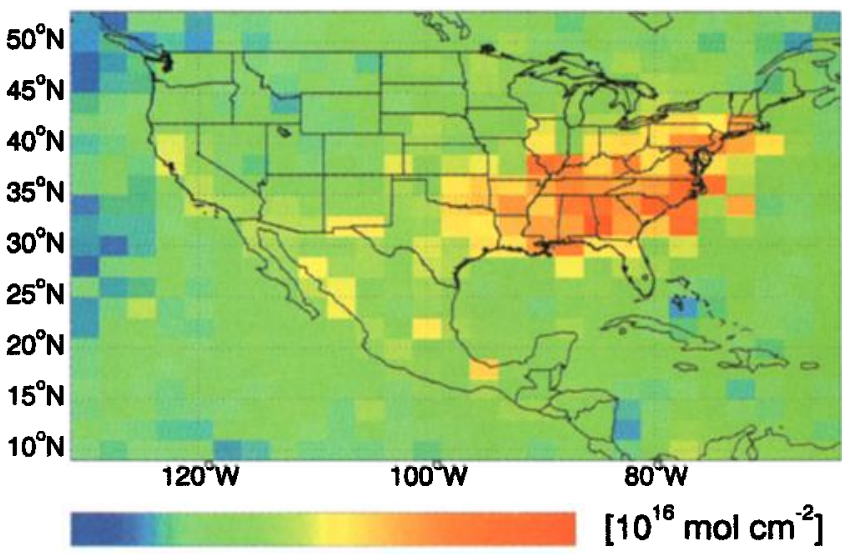

$\begin{array}{llllllllll}0.0 & 0.3 & 0.6 & 0.9 & 1.2 & 1.5 & 1.8 & 2.1 & 2.4 & 2.7\end{array}$

Figure 2. HCHO columns retrieved from the GOME instrument over the U.S. for July 1996. Observations are for 1026-1154 local solar time and for cloud cover less than $40 \%$. Figure $2 a$ shows the geometric total vertical columns and Figure $2 \mathrm{~b}$ show the total vertical columns which account for Rayleigh scattering. 
for low, moderate, and high concentrations of HCHO, plotted as the fitted absorption of $\mathrm{HCHO}$ with and without the fitting residuals.

\section{Results}

HCHO columns have been retrieved for $0^{\circ}-75^{\circ} \mathrm{N}$, $45^{\circ}-180^{\circ} \mathrm{W}$ for the entire month of July 1996 . Results for the North American region, $10^{\circ}-60^{\circ} \mathrm{N}, 65^{\circ}-130^{\circ} \mathrm{W}$, selected for cloud fractional coverage of less than $40 \%$ and binned on a $2^{\circ} \times 2.5^{\circ}$ grid, are shown in Figure $2 \mathrm{a}$, after division by geometric air-mass factors $A \mathrm{AMF}_{\mathrm{G}}$, where $A M F_{\mathrm{G}}$ $=\sec \theta_{s}+\sec \theta_{v}, \theta_{s}$ is the solar zenith angle, and $\theta_{v}$ the satellite viewing zenith angle. The solar zenith angles and solar times corresponding to these measurements range from $15-35^{\circ}$ and $1026-1154$, respectively; the range of satellite viewing angles is $0^{\circ}-31^{\circ}$. The resulting $A M F_{G}$ values range from 2.0 to 2.4 .

Figure 2b shows the vertical columns of $\mathrm{HCHO}$ obtained after determination of AMFs that account for Rayleigh scattering, as described above. These AMFs are in the range 0.7-1.2, about half of the geometric AMFs because most of the $\mathrm{HCHO}$ is in the lower troposphere where scattering inhibits viewing. Variability in the shape of the vertical profile of HCHO in the GEOS-CHEM model induces 20\% variability in the AMFs. We find a large HCHO enhancement over southeastern United States, as expected from the strong regional source contributed by oxidation of isoprene [Lee et al., 1998]. This enhancement is manifest from the spectral analysis alone (Figure $2 a$ ) and is magnified by application of the scattering AMF (Figure 2b). This reflects the a priori information from the GEOS-CHEM model that most of the HCHO column is in the boundary layer (PIP). The HCHO columns over the southeastern U.S. in Figure $2 \mathrm{~b}$ are in the range $2-3 \times 10^{16}$ molecules $\mathrm{cm}^{-2}$. Assuming a typical HCHO scale height of $2 \mathrm{~km}$ [Lee et al., 1998], these columns correspond to boundary layer concentrations of 4-6 ppbv, which are consistent with in situ observations in that region [Munger et al., 1995; Lee et al., 1998].

In the future, this work will be expanded to include detailed studies of HCHO emissions over the U.S. in other years and seasons, and in greater temporal detail, to test estimates of isoprene emission fluxes and identify hot spots. The July 1996 data shown here contain much more detail about local production and transport than is provided in the present overview. We will also extend our analysis to the tropics, where biogenic and biomass burning sources of NMHCs are highly uncertain.

Future work should include improvement in the retrieval of $\mathrm{HCHO}$. With improved HCHO sensitivity, or by merging results over selected regions, we will investigate $\mathrm{HCHO}$ in the remote marine troposphere. Better quantification of HCHO requires improvements in cloud and aerosol determination. Clouds mask the HCHO from observation. Scattering by aerosols alters the effective path length for $\mathrm{HCHO}$ absorption, enhancing or decreasing the observed HCHO absorption, depending on the measurement geometry, the vertical distribution of the aerosol relative to that of HCHO, and the surface albedo. For severe haze events, with scattering aerosol optical depths at $340 \mathrm{~nm}\left(\tau_{340}\right)$ of the order of 2 in the boundary layer, the AMF may increase by $40 \%$ (PIP). Improved cloud parameterization will come from the Cloud Retrieval Algorithm for GOME (CRAG) [Kurosu et al., 1999], which has been developed to provide cloud fractional coverage, cloud-top height, and optical thickness for the GOME scenes.

Acknowledgments. This research is supported at the Smithsonian Astrophysical Observatory and Harvard University by the National Aeronautics and Space Administration, including Atmospheric Chemistry Modeling and Analysis Program Grant NAG1-2153. Additional support was provided by Smithsonian Institution internal funds. R.V. Martin was supported by a National Science Foundation Graduate Fellowship. We thank C. Cantrell for providing the temperature parameterization of the HCHO cross sections, and D. Wilmouth and T. Hanisco for providing $\mathrm{BrO}$ cross sections prior to publication.

\section{References}

Bey, I., D.J. Jacob, R.M. Yantosca, J.A. Logan, B.D. Field, A.M. Fiore, Q. Li, H. Liu, and M.G. Schultz, Asian outflow to the Pacific Ocean in springtime: A 3D simulation of the PEMWest (B) mission with assimilated meteorology, submitted to J. Geophys. Res., August 2000.

Burrows, J.P., K.V. Chance, A.P.H. Goede, R. Guzzi, B.J. Kerridge, C. Muller, D. Perner, U. Platt, J.-P. Pommereau, W. Schneider, R.J. Spurr, and H. van der Woerd, Global Ozone Monitoring Experiment Interim Science Report, ed. T. D. Guyenne and C. Readings, Report ESA SP-1151, ESA Publications Division, ESTEC, Noordwijk, The Netherlands, ISBN 92-9092-041-6, 1993.

Cantrell, C.A., J.A. Davidson, A.H. McDaniel, R.E. Shetter, and J.G. Calvert, Temperature-dependent formaldehyde cross sections in the near-ultraviolet spectral region, J. Phys. Chem. 94, 3902-3908, 1990.

Caspar, C., and K. Chance, GOME wavelength calibration using solar and atmospheric spectra, Proc. Third ERS Symposium on Space at the Service of our Environment, Ed. T.-D. Guyenne and D. Danesy, European Space Agency publication SP-414, ISBN 92-9092-656-2, 1997.

Chance, K., and R.J.D. Spurr, Ring effect studies: Rayleigh scattering, including molecular parameters for rotational Raman scattering, and the Fraunhofer spectrum, Appl. Opt. 36, 5224$5230,1997$.

Chance, K., Analysis of BrO measurements from the Global Ozone Monitoring Experiment, Geophys. Res. Lett. 25, 33353338, 1998.

European Space Agency, The GOME Users Manual, ed. F. Bednarz, European Space Agency Publication SP-1182, ESA Publications Division, ESTEC, Noordwijk, The Netherlands, ISBN-92-9092-327-x, 1995.

Guenther, A., C. Geron, T. Pierce, B. Lamb, P. Hatley, and R. Fall, Natural emissions of non-methane volatile organic compounds, carbon monoxide, and oxides of nitrogen from North America, Atmos. Env. 34, 2205-2230, 2000.

Horowitz, L.W., J. Liang, G.M. Gardner, and D.J. Jacob, Export of reactive nitrogen from North America during summertime: Sensitivity to hydrocarbon chemistry, J. Geophys. Res. 103, 13,451-13,476, 1998.

Kurosu, T.P., K.V. Chance and R.J.D. Spurr, CRAG - Cloud Retrieval Algorithm for ESA's Global Ozone Monitoring Experiment, Proc. 1999 European Symposium on Atmospheric Measurements from Space, ESA WPP-161, 513-521, 1999.

Lee Y.-N., et al., Atmospheric chemistry and distribution of formaldehyde and several multioxygenated carbonyl compounds during the 1995 Nashville/Middle Tennessee Ozone Study, $J$. Geophys. Res. 103, 22,449-22,462, 1998.

Logan, J.A., M.J. Prather, S.C. Wofsy, and M.B. McElroy, Tropospheric chemistry: A global perspective, J. Geophys. Res. 86, 7210-7254, 1981.

McKeen, S.A., E.-Y. Hsie, and S.C. Liu, A study of the dependence of rural ozone on ozone precursors in the Eastern United States, J. Geophys. Res. 96, 15,377-15,394, 1991.

McKeen, S.A., et al., Photochemical modeling of hydroxyl and 
its relationship to other species during the Tropospheric $\mathrm{OH}$ Photochemistry Experiment, J. Geophys. Res. 102, 6467-6493, 1997.

Moxim, W.J., H. Levy II, and P.S. Kasibhatla, Simulated global tropospheric PAN: Its transport and impact on $\mathrm{NO}_{\mathbf{x}}, J$. Geophys. Res. 101, 12,621-12,638, 1996.

Munger, J.W., D.J. Jacob, B.C. Daube, L.W. Horowitz, W.C. Keene, and B.G. Heikes, Formaldehyde, glyoxal, and methylglyoxal at a rural mountain site in central Virginia, J. Geophys. Res. 100, 9325-9334, 1995.

Penner, J.E., Carbonaceous aerosols influencing atmospheric radiation: Black and organic carbon, in Aerosol Forcing of Climate, edited by R.J. Charlson and J. Heintzenberg, pp. 91-108, J. Wiley \& Sons, 1995.

Pierson, W.R., A.W. Gertler, and R.L. Bradow, Comparison of the SCAQS tunnel study with other on-road vehicle emission data, J. Air Waste Manage. Assoc. 40, 1495-1504, 1990.

Press, W.H., B.P. Flannery, S.A. Teukolsky, and W.T. Vetterling, Numerical Recipes, ISBN 0-521-30811-9, Cambridge University Press, 1986.

Slijkhuis, S., A. von Bargen, W. Thomas, and K. Chance, Calculation of undersampling correction spectra for DOAS spectral fitting, Proc. ESAMS'99 - European Symposium on Atmospheric Measurements from Space, ESA WPP-161, ISSN 1022-6656, 563-569, 1999.
Spurr, R.J.D., T.P. Kurosu and K.V. Chance A linearized discrete ordinate radiative transfer model for atmospheric remote sensing retrieval, J. Quant. Spectrosc. Rad. Transfer, in press, 2000.

Staffelbach, T., A. Neftel, B. Stauffer, and D.J. Jacob, Formaldehyde in polar ice cores: A possibility to characterize the atmospheric sink of methane in the past?, Nature $349,603-605$, 1991.

Thomas, W., E. Hegels, S. Slijkhuis, R. Spurr, and K. Chance, Detection of biomass burning combustion products in Southeast Asia from backscatter data taken by the GOME spectrometer, Geophys. Res. Lett. 25, 1317-1320, 1998.

K. Chance, T.P. Kurosu, and R.J.D. Spurr, 60 Garden Street, Cambridge, MA 02138

(email: kchance; tkurosu; rspurr@cfa.harvard.edu)

D.J. Jacob, R.V. Martin, and P.I. Palmer, 29 Oxford Street, Cambridge, MA 02138

(email: djj; rvm; pip@io.harvard.edu)

(Received June 9, 2000; revised July 25, 2000 accepted September 18, 2000.) 